\title{
Macronutrientes e produtividade da forragem hidropônica de milho fertilizado com soluções compostas por águas amarelas
}

Esta pesquisa objetivou avaliar os teores de macronutrientes e a produtividade na forragem verde hidropônica de milho cultivado em bagaço de cana-de-açúcar fertilizado com solução de urina humana associada à manipueira. O experimento foi realizado em uma casa de vegetação instalada no Campus I da Universidade Federal de Campina Grande. Utilizou-se delineamento experimental em blocos ao acaso composto por seis tratamentos distribuídos em quatro blocos. Os tratamentos consistiram por fertilizações com doses de $0,1,2,3,4$ e 5\% de urina humana com pH ajustado para 6,4 com manipueira. Para efeito dos tratamentos foram avaliadas a produtividade e teores de nutrientes na parte aérea e substrato com raízes da forragem. Os resultados indicada resposta significativa ( $p<0,05)$ para as massas verde e seca da parte aérea e teores dos macronutrientes ( N , P, K, Ca e S) da forragem, de forma que as doses de urina humana associada à manipueira exerceram influência na incorporação destes elementos na parte aérea e substrato com raízes. Conclui-se que o uso da urina humana associada à manipueira mostrou-se eficaz para a fertilização do milho cultivado em sistema hidropônico, podendo substituir a solução nutritiva utilizada convencionalmente no cultivo da forragem hidropônica de milho.

\section{Macronutrients and productivity of hydroponic forage of maize fertilized with solutions composed by yellow waters}

\begin{abstract}
The objective of this research was to evaluate macronutrient contents and yield in the hydroponic green forage of maize grown in sugarcane bagasse fertilized with human urine solution associated to the cassava wastewater. The experiment was carried out in a greenhouse located at Campus I, Federal University of Campina Grande. A randomized complete block design was used, consisting of six treatments distributed in four blocks. Treatments consisted of fertilizations with doses of $0,1,2,3,4$ and $5 \%$ of human urine with $\mathrm{pH}$ adjusted to 6.4 with cassava wastewater. For the purpose of the treatments were evaluated the productivity and nutrient contents in the aerial part and substrate with roots of the forage. The results indicated a significant response $(p<0.05)$ for green and dry shoot mass and macronutrient (N, P, K, Ca and S) contents of the forage, so that the doses of human urine associated with the cassava wastewater exerted influence in the incorporation of these elements in the aerial part and substrate with roots. It is concluded that the use of human urine associated with the cassava wastewate was effective for the fertilization of maize grown in a hydroponic system, and could replace the nutrient solution conventionally used in the cultivation of corn hydroponic fodder.
\end{abstract}

Keywords: Zea Mays L.; Cassava Wastewater; Human Urine; Nutrient Recycling; Ecological Sanitation.

Topic: Experimentação Agrícola

Reviewed anonymously in the process of blind peer.
Received: 10/08/2018

Approved: 24/09/2018
Narcísio Cabral de Araújo (iD

Universidade Federal do Sul da Bahia, Brasil http://lattes.cnpq.br/7850461835909726

http://orcid.org/0000-0003-0589-8924

narcisioufsb@gmail.com

\section{Rui de Oliveira (D)}

Universidade Estadual da Paraíba, Brasil http://lattes.cnpq.br/0621382505832223

http://orcid.org/0000-0003-3767-2233

ruideo@gmail.com

Mônica de Amorim Coura

Universidade Federal de Campina Grande, Brasil

http://orcid.org/0000-0001-5820-9315

macoura1@yahoo.com.br
Francisco de Assis Bandeira

Universidade Federal de Campina Grande, Brasil http://lattes.cnpq.br/5872868840921404

http://orcid.org/0000-0001-5576-3732

tiquinhobandeira@hotmail.com
Referencing this:

ARAÚJO, N. C.; OLIVEIRA, R.; COURA, M. A.; BANDEIRA, F. A. Macronutrientes e produtividade da forragem hidropônica de milho fertilizado com soluções compostas por águas amarelas. Revista Ibero Americana de Ciências Ambientais, v.9, n.7, p.42-51, 2018. DOI: http://doi.org/10.6008/CBPC2179-6858.2018.007.0005 


\section{INTRODUÇÃO}

Recentemente, a técnica de hidroponia foi adaptada para a produção de volumoso de milho, para servir de alimento a bovinos, na época da seca, com custo de produção mais baixo do que o de pastagens convencionais e com valor nutritivo alto, principalmente em proteínas, devido à fase em que as plantas são colhidas e disponibilizadas para a alimentação dos animais (ARAÚJO et al., 2008). A utilização de resíduos como fertilizantes na atividade agrícola pode trazer benefícios ao desenvolvimento da cultura (MAGALHÃES et al., 2014).

Um efluente que vem sendo muito avaliado em experimentos agrícola é a manipueira que é o líquido de constituição das raízes de mandioca, que apresenta aspecto leitoso, cor amarela-clara, odor fétido (ARAÚJO et al., 2014) e potencial de uso para fertilização de plantas em cultivo orgânico, por conter macro e micronutrientes (MARINI et al., 2011; CONCEIÇÃO et al., 2013). Outro efluente com potencial para o uso agrícola é a urina humana (água amarela), pois segundo Karak et al. (2011) é também bastante rica em macro e micronutrientes.

Segundo Mihelcic et al. (2011) e Louro et al. (2012) as tecnologias de reciclar nutrientes de urina humana tem se demostrado bastante viável, tanto para os países subdesenvolvidos como para os desenvolvidos e que a reciclagem de nutrientes da urina para fins agrícolas é uma boa alternativa para solucionar o problema da escassez de rochas ricas em fosfatos, que futuramente pode gerar impactos na fabricação de fertilizantes e na produção de alimentos. Portanto, este trabalho objetivou avaliar os teores de macronutrientes e a produtividade da forragem verde hidropônica de milho (Zea mays L.) cultivado em bagaço de cana-de-açúcar fertilizado com diferentes doses de urina humana associada à manipueira, como solução nutritiva.

\section{MATERIAIS E MÉTODOS}

O experimento foi realizado, entre os meses de maio a junho de 2013 em uma casa de vegetação instalada no Campus I da Universidade Federal de Campina Grande, na Cidade de Campina Grande (70 13’ 50" S, 350 52' 52" W , 551 m de altitude) no estado da Paraíba, Brasil. A casa de vegetação foi construída com estrutura de madeira, modelo 'capela', com $5 \mathrm{~m}$ de comprimento, $3 \mathrm{~m}$ de largura e 2,5 m de altura e revestida por cortinamento lateral, com telas fina de polipropileno, com capacidade para reter $30 \%$ da luz e coberta com polietileno de baixa densidade (PEBD), ambiente controlado quanto à radiação solar e precipitações. No interior da casa de vegetação foram instaladas duas bancadas para suportar as células hidropônicas (bandejas de plástico com $45 \mathrm{~cm}$ de comprimento, $29 \mathrm{~cm}$ de largura e 4,0 cm de profundidade).

Foi utilizado o delineamento experimental em blocos ao acaso, composto por quatro blocos e seis tratamentos, o que correspondeu a 24 células hidropônicas, distanciadas $15 \mathrm{~cm}$ entre si e com $2 \%$ de declividade. O sistema hidropônico utilizado foi de três fases (líquido com nutriente, ar e substrato) e não circulante (sem recirculação das soluções fertilizante), com utilização de bagaço de cana-de-açúcar como substrato vegetal. $\mathrm{O}$ substrato foi analisado quimicamente e apresentou as seguintes características: 6,83 
g. $\mathrm{kg}^{-1}$ de nitrogênio; $3,23 \mathrm{~g} \cdot \mathrm{kg}^{-1}$ de fósforo; $4,36 \mathrm{~g} \cdot \mathrm{kg}^{-1}$ de potássio; $0,10 \mathrm{~g} \cdot \mathrm{kg}^{-1}$ de cálcio; $0,19 \mathrm{~g} \cdot \mathrm{kg}^{-1}$ de sódio; $5,90 \mathrm{mg} \cdot \mathrm{kg}^{-1}$ de enxofre e $62,7 \mathrm{mg} \cdot \mathrm{kg}^{-1}$ de ferro.

Em cada célula hidropônica foram espalhadas $150 \mathrm{~g}$ de bagaço de cana-de-açúcar e feita a semeadura do milho. Foram utilizadas sementes de milho não tratadas quimicamente, com densidade de semeadura de 2,5 kg. $\mathrm{m}^{-2}$, de acordo com FAO (2001), ou seja, em cada célula $\left(0,1305 \mathrm{~m}^{2}\right)$ foram semeados $326,3 \mathrm{~g}$ do milho. Para acelerar o processo de emergência, antes da semeadura, as sementes foram submetidas à hidratação, sendo embebidas em água por período de 24 horas (pré-germinação). Após este tempo e, feita a drenagem da água, foi procedida à semeadura, a lanço. Em seguida, as sementes foram cobertas com outra camada homogênea de $120 \mathrm{~g}$ do substrato.

Durante o período de emergência das sementes ( 5 dias após a semeadura - DAS) as células eram irrigadas três vezes ao dia com apenas água de abastecimento. Após este período, foram iniciadas as fertilizações, ou seja, diariamente e parceladas em três vezes, cada célula era fertirrigada com taxa de aplicação de $5 \mathrm{~L} . \mathrm{m}^{-2} \cdot \mathrm{d}^{-1}$, com as soluções que foram caracterizados pelos seguintes tratamentos: 1 (testemunha) - Solução nutritiva utilizada no cultivo de forragem verde hidropônica (FAO, 2001) e cinco soluções compostas por 1, 2, 3, 4 e 5\% de urina humana diluída em água com pH ajustado para 6,4 com manipueira, ou seja, para ajustar o pH das diluições de urina foram utilizados os seguintes volumes de manipueira por litro da diluição: 20; 35; $45 ; 67,5$ e $87,5 \mathrm{~mL}$, respectivamente. A manipueira foi adicionada em cada diluição de urina para ajustar o pH para 6,4 pois, segundo recomendações da FAO (2001), o pH da solução nutritiva utilizada no cultivo da forragem verde hidropônica deve estar entre 5,2 e 7,0.

A solução nutritiva utilizada no tratamento 1 , foi preparada a partir de duas soluções concentradas (' $A$ ' e ' $B$ '). A solução 'A' foi constituída por: monofosfato de amônio, nitrato de cálcio e nitrato de potássio e a solução 'B' por: sulfato de magnésio, sulfato de cobre, sulfato de manganês, sulfato de zinco, ácido bórico, molibdato de amônio e quelatos de ferro. Estas soluções foram preparadas de acordo com as recomendações do Manual Técnico da FAO (2001). Diariamente, antes da irrigação, eram preparados 4 litros contendo respectivamente, $1,25 \mathrm{~mL}$. L ${ }^{-1}$ da solução ' $A$ ' e $0,5 \mathrm{~mL}$. $\mathrm{L}^{-1}$ da solução ' $B$ '.

A urina humana utilizada foi coletada por um período de sete dias consecutivos, em três residências no município de Campina Grande, e armazenada em um recipiente hermeticamente fechado, por período de um mês, antes de começar a ser utilizada. Já a manipueira foi coletada na mesma semana da sua utilização sendo adquirida em uma casa de farinha no município de Puxinanã, PB.

Na Tabela 1 estão os parâmetros da caracterização físico-química da solução nutritiva (tratamento 1), diluições de urina humana adicionada de manipueira (tratamentos $2,3,4,5$ e 6), urina humana (U) e manipueira (M) que faram analisados, segundo metodologia preconizada no Standard Methods for Wastewater (APHA, 2005).

Os tratamentos foram aplicados até o 9o dia após a emergência (DAE). As regas eram realizadas manualmente com auxílio de um minirregador, confeccionado a partir de uma pinceta. O líquido percolado em cada célula era drenado, através de drenos com $3 \mathrm{~mm}$ de diâmetro, para garrafas PET, sendo descartado posteriormente. 
Tabela 1: Caracterização físico-química das soluções nutritivas (tratamentos), urina humana e manipueira utilizada no experimento.

\begin{tabular}{|c|c|c|c|c|c|c|c|c|c|}
\hline \multirow{3}{*}{ Tratamentos } & \multicolumn{9}{|c|}{ Parâmetros } \\
\hline & NTK & $\mathrm{N}-\mathrm{NH}_{3}$ & PT & $\mathrm{PO}_{4}^{-3}$ & $\mathrm{~K}$ & $\mathrm{Cl}^{-}$ & $\mathrm{Na}$ & $\mathrm{pH}$ & CE \\
\hline & \multicolumn{7}{|c|}{. } & - & $\mathrm{mS} \mathrm{cm}^{-1}$ \\
\hline 1 & 3,0 & 2,40 & 12,17 & 9,26 & 7,27 & 269,54 & 15,99 & 7,0 & 1,689 \\
\hline 2 & 85,25 & 60,03 & 12,97 & 9,99 & 2,62 & 303,54 & 15,14 & 6,4 & 2,17 \\
\hline 3 & 156,68 & 124,87 & 20,64 & 15,13 & 5,16 & 395,82 & 16,58 & 6,4 & 2,44 \\
\hline 4 & 234,12 & 212,51 & 30,72 & 20,47 & 6,83 & 497,81 & 18,32 & 6,4 & 2,98 \\
\hline 5 & 286,95 & 288,15 & 44,44 & 27,50 & 10,32 & 556,09 & 20,12 & 6,4 & 3,68 \\
\hline 6 & 396,21 & 360,19 & 54,93 & 30,35 & 13,46 & 638,65 & 21,62 & 6,4 & 4,25 \\
\hline $\mathrm{U}$ & 6889,40 & 5759,79 & 403,92 & 392,85 & 201,56 & 6103,19 & 674,66 & 9,0 & 42,63 \\
\hline$M$ & 968,24 & 218,47 & 419,69 & 250,53 & 475,26 & 760,87 & 98,53 & 4,17 & 7,68 \\
\hline
\end{tabular}

NTK: Nitrogênio Total Kjeldahl; $\mathrm{N}-\mathrm{NH}_{3}$ : Nitrogênio Amoniacal; PT: Fósforo total; $\mathrm{PO}_{4}^{-3}$ : Ortofosfato solúvel; K: Potássio; $\mathrm{Cl}^{-2}$ Cloreto; $\mathrm{Na}$ : Sódio; pH: Potencial hidrogeniônico; CE: Condutividade Elétrica; U: urina humana e M: Manipueira.

No 10 DAE as células foram irrigadas com apenas água e no 11으 DAE foi coletada a parte aérea e raízes com substrato da forragem (cortando as plantas com um estilete rente ao substrato). Após o fracionamento foram determinadas a massa fresca da parte aérea (MFPA) e massa fresca do substrato com raízes (MFSR), através de suas pesagens em uma balança com precisão de 1,0 mg. Após as determinações das massas verdes, a parte aérea e substrato com raízes foram colocados em sacos de papel, previamente furados e identificados, para secagem em estufa com temperatura controlada $(65 \stackrel{\circ}{ }$ ) e circulação forçada de ar, por um período de 72 horas. Assim, após a secagem, foram determinadas massa seca da parte aérea (MSPA) e massa seca do substrato com raízes (MSRS).

As amostras secas foram trituradas em moinho tipo Willey para as determinações das concentrações de nitrogênio $(\mathrm{N})$, fósforo $(\mathrm{P})$, potássio $(\mathrm{K})$, cálcio $(\mathrm{Ca})$ e enxofre $(\mathrm{S})$. As análises de $\mathrm{N}$ e $\mathrm{P}$ foram realizadas através da metodologia descrita por Rodrigues (2010) e as demais segundo Silva (2009).

Os resultados das variáveis, produtividade (MFPA, MSPA, MFRS e MSRS), nutrientes ( $N, P, K$, Ca e S) foram interpretados estatisticamente, por meio de análise de variância e de regressão, utilizando-se o software ASSISTAT - Assistência Estatística, versão 7.7 Beta (SILVA et al., 2016). A escolha dos modelos, em cada variável estudada, baseou-se no coeficiente de determinação $\left(R^{2}\right)$ fornecido pela análise, tendo sido adotado o teste $\mathrm{F}$ para verificar a significância dos efeitos.

\section{RESULTADOS E DISCUSSÃO}

A análise de variância aplicada aos teores dos macronutrientes (N, P, K, Ca e S) mostrou respostas significativas $(p<0,01)$ sobre os efeitos das doses de urina humana associada à manipueira na incorporação destes elementos na parte aérea e substrato com raízes da forragem hidropônica de milho (Tabela 2). 0 comportamento das concentrações de $\mathrm{N}, \mathrm{P}, \mathrm{K}, \mathrm{Ca}$ e $\mathrm{S}$ na parte aérea e no substrato com raízes da forragem estão ilustrados na Figura 1. Observando as Figuras 1A e 1B pode-se constatar que todos os tratamentos com urina humana associada à manipueira apresentaram concentrações de nitrogênio superiores à testemunha. Na parte aérea a máxima concentração foi de $48,56 \mathrm{gN} \mathrm{kg}^{-1}$ e no substrato com raízes foi de $18,63 \mathrm{gN} \mathrm{kg}^{-1}$ quando era aplicada solução de $4 \%$ de urina com manipueira. O modelo matemático que melhor descreveu o comportamento da concentração de $\mathrm{N}$ foi o linear crescente, com coeficientes de determinação de $92,73 \%$ e $92,50 \%$ na parte aérea e substrato com raízes, respectivamente. 
Tabela 2: Resumo dos quadrados médios da análise de variância das determinações química de nitrogênio (N), fósforo $(\mathrm{P})$, potássio $(\mathrm{K})$, cálcio $(\mathrm{Ca})$ e enxofre $(\mathrm{S})$ da fitomassa da parte aérea (PA) e raízes com substrato (RS) de milho forrageira, fertilizado com urina e manipueira

\begin{tabular}{|l|l|l|l|l|l|c|}
\hline $\mathrm{FV}(\mathrm{PA})$ & $\mathrm{GL}$ & $\mathrm{N}$ & $\mathrm{P}$ & $\mathrm{K}$ & $\mathrm{Ca}$ & $\mathrm{S}$ \\
\hline Regressão Linear & 1 & $122,456^{* *}$ & $2,676^{* *}$ & $256,022^{* *}$ & $12223,214^{* *}$ & $10,426^{* *}$ \\
\hline Regressão Quadrática & 1 & $1,643^{\text {ns }}$ & $0,054^{\text {ns }}$ & $3,719^{\text {ns }}$ & $900,298^{\text {ns }}$ & $0,97523^{\text {ns }}$ \\
\hline Desvio de Regressão & 3 & $2,722^{\text {ns }}$ & $0,025^{\text {ns }}$ & $22,765^{*}$ & $2394,841^{\text {ns }}$ & $0,963^{\text {ns }}$ \\
\hline (Tratamento) & $(5)$ & $26,413^{* *}$ & $0,575^{* *}$ & $58,721^{* *}$ & $3104,167^{* *}$ & $2,473^{* *}$ \\
\hline Bloco & 3 & 13,243 & 0,690 & 1,976 & 659,722 & 2,294 \\
\hline Resíduo & 15 & 2,837 & 0,241 & 2,444 & 493,056 & 1,139 \\
\hline CV\% & - & 3,67 & 5,33 & 9,14 & 15,91 & 15,05 \\
\hline FV (SR) & $\mathrm{GL}$ & $\mathrm{N}$ & $\mathrm{P}$ & $\mathrm{K}$ & $\mathrm{Ca}$ & $\mathrm{S}$ \\
\hline Regressão Linear & 1 & $54,279^{* *}$ & $0,746^{* *}$ & $4,159^{* *}$ & $8580,357^{* *}$ & $114,733^{* *}$ \\
\hline Regressão Quadrática & 1 & $1,014^{\text {ns }}$ & $0,015^{\text {ns }}$ & $0,403^{\text {ns }}$ & $66,964^{\text {ns }}$ & $8,339^{* *}$ \\
\hline Desvio de Regressão & 3 & $1,193^{\text {ns }}$ & $0,040^{\text {ns }}$ & $0,072^{\text {ns }}$ & $2089,286^{\text {ns }}$ & $2,997^{* *}$ \\
\hline (Tratamento) & $(5)$ & $11,736^{* *}$ & $0,160^{* *}$ & $1,079^{* *}$ & $2187,500^{* *}$ & $26,139^{* *}$ \\
\hline Bloco & 3 & 1,206 & 0,031 & 0,626 & 381,944 & 0,252 \\
\hline Resíduo & 15 & 0,632 & 0,027 & 0,185 & 465,278 & 0,083 \\
\hline CV\% & - & 4,75 & 6,09 & 13,04 & 9,86 & 5,09 \\
\hline
\end{tabular}

${ }^{* *}$ : Significativo a 1\% de probabilidade (Teste F); ${ }^{*}$ : Significativo a 5\% de probabilidade (Teste F); ns: não significativo (Teste F); FV (PA): Fonte de Variação da parte aérea FV (SR): Fonte de Variação do substrato com raízes; GL: Grau de liberdade e CV: Coeficiente de Variação.

Os teores de nitrogênio encontrados na parte aérea da forragem foram superiores aos citados na literatura, pois Müller et al. (2005) e Amorim et al. (2005), cultivando milho em sistema hidropônico, encontram teores de proteína bruta de $18,25 \%$ que corresponde a $\left(29,2 \mathrm{gN} \mathrm{kg}^{-1}\right)$ e $13,1 \%\left(20,96 \mathrm{gN} \mathrm{kg}^{-1}\right)$, respectivamente.

A equação que melhor descreveu a incorporação do fósforo na parte aérea e substrato com raízes da forragem, foi a linear crescente com coeficientes de determinação de 93,10 e 93,17\% para a parte aérea (Figura 1C) e substrato com raízes (Figura 1D), respectivamente. Na parte aérea a máxima concentração de P foi obtida quando da aplicação de $4 \%$ de urina com manipueira, correspondendo a um incremento de $8,98 \%$ em relação à testemunha. $\mathrm{O}$ substrato com raízes apresentou a máxima concentração de $\mathrm{P}$ quando da aplicação das máximas doses de urina associada à manipueira, sendo o incremento de 16,0\% em relação à testemunha.

As concentrações de potássio na parte aérea e substrato com raízes da forragem apresentaram comportamento linear crescente com coeficientes de determinação de 95,0\% para a parte aérea (Figura 1E) e $77,09 \%$ para o substrato com raízes (Figura 1F). Os incrementos do elemento foram de $37,22 \%$ na parte aérea e $28,68 \%$ no substrato com raízes, com relação à testemunha.
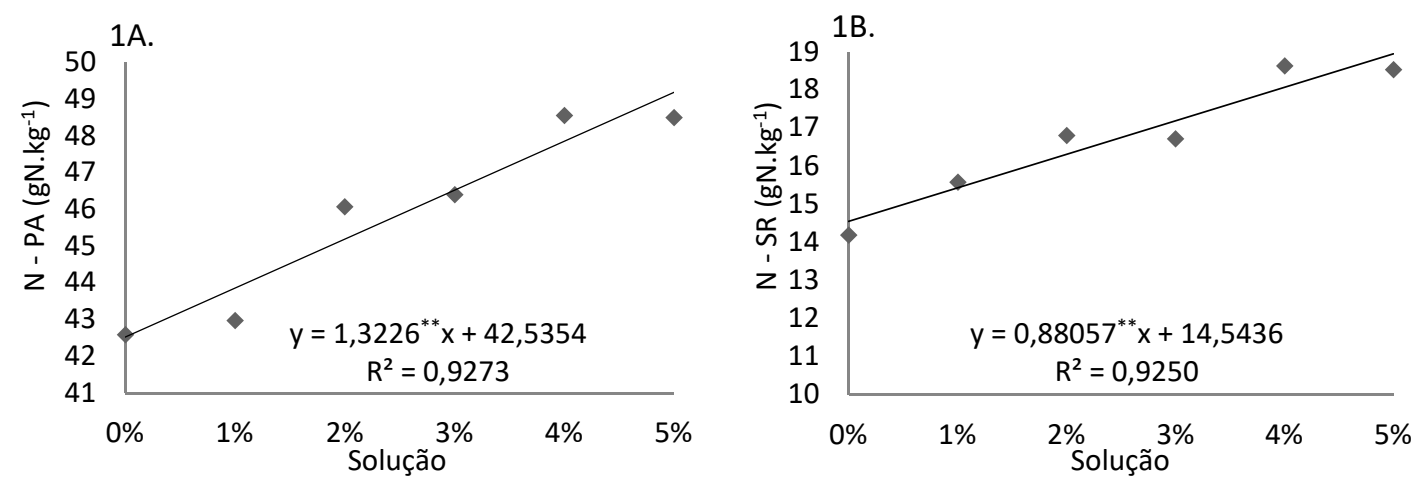

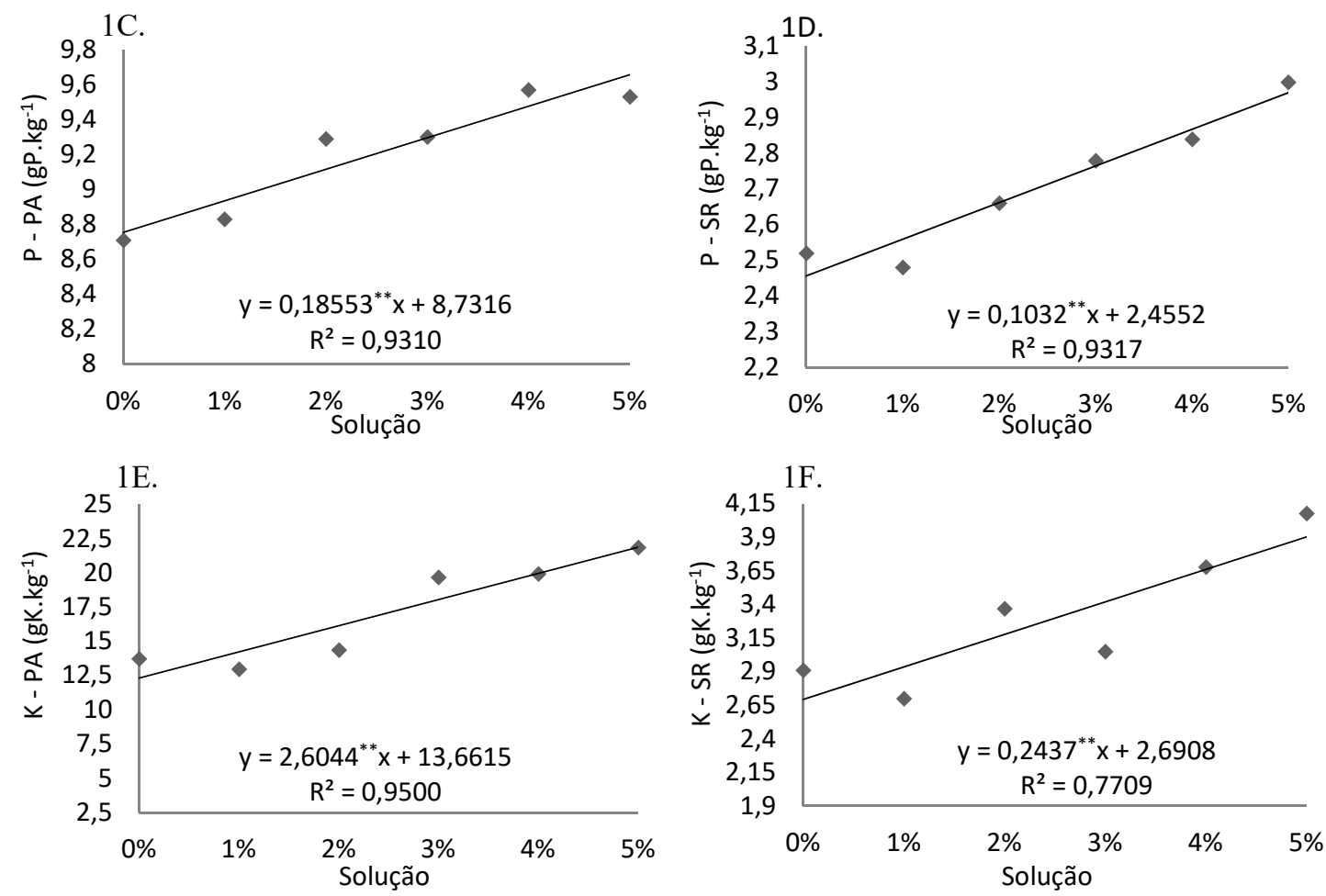

Figura 1: Concentrações (g.kg ${ }^{-1}$ ) de nitrogênio (1A e 1B), fósforo (1C e 1D) e potássio (1E e 1F) na parte aérea (PA) e substrato com raízes (SR) em função das doses de urina associada a manipueira aplicadas na fertilização da forragem verde hidropônica de milho.

De acordo com a Figura 2, o cálcio apresentou comportamento similar ao do potássio, ou seja, acréscimo linear na parte aérea (Figura $2 \mathrm{~A}, \mathrm{R}^{2}$ de $78,75 \%$ ) e substrato com raízes (Figura $2 \mathrm{~B}, \mathrm{R}^{2}$ de $78,45 \%$ ). Os incrementos foram de $28,57 \%$ para a parte aérea e $20 \%$ no substrato com raízes, sendo que as concentrações do elemento na parte aérea foram inferiores às do substrato com raízes.

As doses crescentes de urina humana associada à manipueira proporcionaram acúmulo de enxofre na parte aérea e substrato com raízes da forragem (Figuras 2C e 2D). Na parte aérea o acúmulo do elemento foi linear (Figura 2C, $\mathrm{R}^{2}$ de $99,99 \%$ ) com incremento máximo de $28,66 \%$ com a dose máxima, e no substrato com raízes o efeito foi quadrático (Figura 2D, $R^{2}$ de $99,99 \%$ ) com acúmulo máximo de $64,44 \%$, em relação ao tratamento testemunha (1).
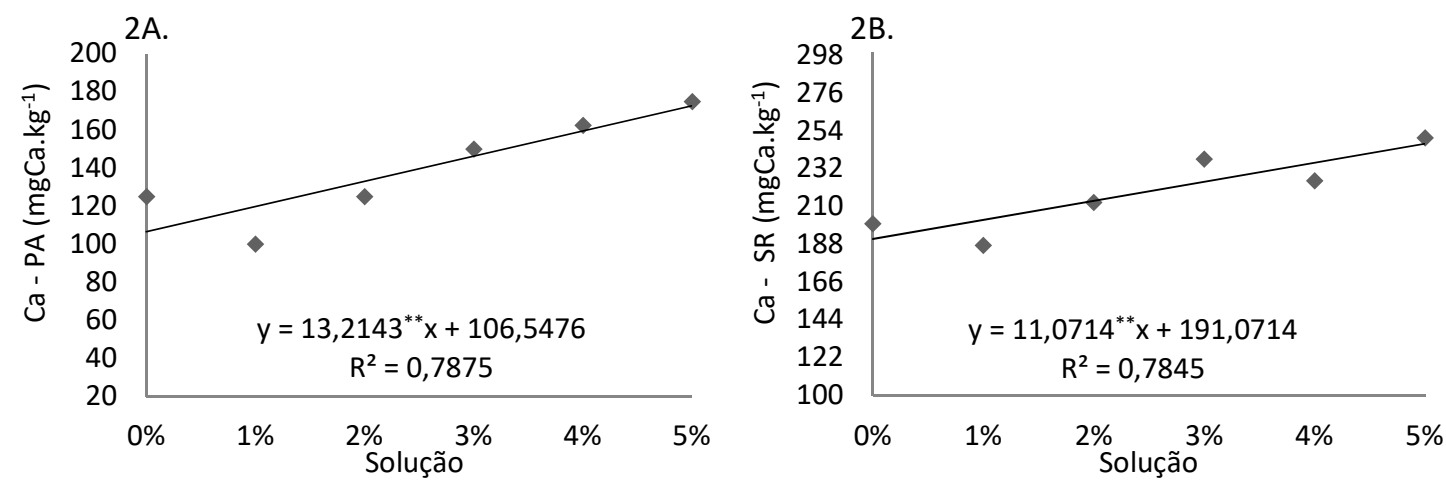

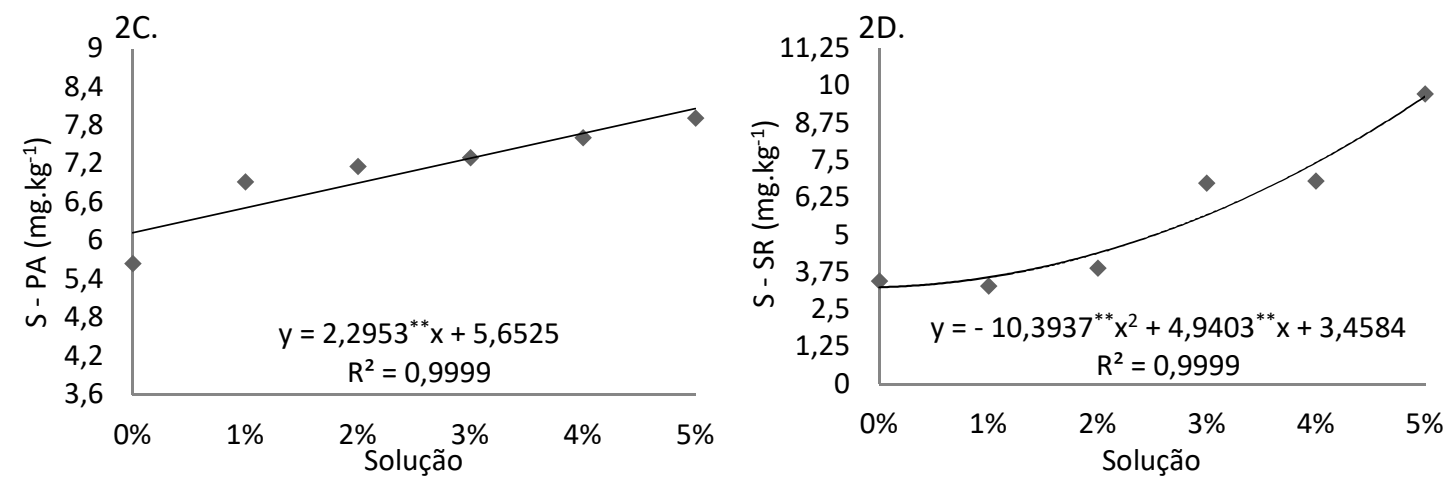

Figura 2: Concentrações (g.kg-1) de cálcio (2A e 2B) e enxofre (2C e 2D) na parte aérea (PA) e substrato com raízes (SR) em função das doses de urina associada à manipueira aplicadas na fertilização da forragem verde hidropônica de milho.

Na presente pesquisa, as fertilizações com dose maior ou igual 3\% de urina associada à manipueira, proporcionaram concentrações dos macronutrientes superiores ao tratamento testemunha (tratamento 1 , $0 \%$ de urina + manipueira) com acréscimo linear na parte aérea para $\mathrm{N}, \mathrm{P}, \mathrm{K}, \mathrm{Ca}$, S e no substrato com raízes para $\mathrm{N}, \mathrm{P}, \mathrm{K}$ e Ca. Apenas as concentrações de S no substrato com raízes foi que apresentou acréscimo quadrático. Os acréscimos nos teores dos macronutrientes analisados na parte aérea e o substrato com raízes da forragem, observados com o aumento das doses de urina humana associada à manipueira podem ser atribuídos as elevadas concentração dos macronutrientes quantificados nas soluções.

Estes resultados corroboram com os encontrados por Araújo et al. (2015) que ao analisarem o uso de diferentes concentrações de urina humana com pH ajustado com solução de ácido sulfúrico na fertilização da forragem verde hidropônica de milho, obtiveram respostas significativa com acréscimo nas concentrações de N, P, K, Ca e S na parte aérea e substrato com raízes da forragem.

De acordo com os resultados obtidos, observa-se que a partir das doses contendo $3 \%$ de urina, as necessidades dos principais macronutrientes $(\mathrm{N}, \mathrm{P}$ e $\mathrm{K}$ ) requeridas pela cultura do milho foram supridas, pois segundo Silva (2009) as faixas de N, P e K consideradas adequadas são de 27 a $35 \mathrm{gN} \mathrm{kg}^{-1}$; 2,0 a 4,0 gP kg e $^{-1}$ 17 a $35 \mathrm{gK} \mathrm{kg}^{-1}$, respectivamente.

Em conformidade com Tokarnia et al. (2000) os elementos P e K são elementos indispensáveis aos processos metabólicos dos ruminantes e por esta razão devem estar presentes na alimentação animal. Além de suprir a necessidade nutricional da cultura, também apresentou volor nutricional significativo para os animais, pois Segundo Lamb et al. (2008) e Wilde (2006) os elementos minerais estão envolvidos nas vias metabólicas dos animais tendo funções importantes na performance reprodutiva, na manutenção do crescimento, no metabolismo energético, na função imune entre outras funções fisiológicas do animal.

Em conformidade com a Tabela 3, a análise de variância constatou efeito significativa $(p<0,05)$ das doses de urina humana associada à manipueira sobre as variáveis massas fresca e seca da parte aérea (MFPA e MSPA), indicando que as fertilizações exerceram influência positiva na produtividade da forragem hidropônica de milho. Porém, as massas fresca e seca do substrato com raízes (MFSR e MSSR, respectivamente) não apresentaram diferença estatística significativa, entre os tratamentos. 
Tabela 3: Resumo dos quadrados médios da análise de variância da produtividade da forragem verde do milho fertilizado com soluções de urina associada à manipueira.

\begin{tabular}{|l|l|l|l|l|c|}
\hline FV & GL & MFPA & MSPA & MFSR & MSSR \\
\hline Regressão Linear & 1 & $0,571^{*}$ & $0,00782^{*}$ & $0,045^{\text {ns }}$ & $0,014^{\text {ns }}$ \\
\hline Regressão Quadrática & 1 & $0,021^{\text {ns }}$ & $0,00022^{\text {ns }}$ & $3,404^{\text {ns }}$ & $0,007^{\text {ns }}$ \\
\hline Desvio de Regressão & 3 & $1,019^{*}$ & $0,00003^{\text {ns }}$ & $2,294^{\text {ns }}$ & 0,044 \\
\hline (Tratamento) & $(5)$ & $0,333^{* *}$ & $0,00185^{* *}$ & $4,953^{* *}$ & $0,013^{* *}$ \\
\hline Bloco & 3 & 1,164 & 0,00256 & 6,803 & 0,016 \\
\hline Resíduo & 15 & 0,082 & 0,00111 & 4,130 & 0,013 \\
\hline CV\% & - & 4,59 & 6,58 & 11,98 & 4,74 \\
\hline
\end{tabular}

${ }^{* *}$ : Significativo a $1 \%$ de probabilidade (Teste F); ${ }^{*}$ : Significativo a $5 \%$ de probabilidade (Teste F); ns: não significativo (Teste F); FV: Fonte de Variação; GL: Grau de Liberdade; AF: Altura da Forragem; MFPA: Massa Fresca da Parte Aérea; MSPA: Massa Seca da Parte Aérea; MFSR: Massa Fresca do Substrato com Raízes; MSSR: Massa Seca do Substrato com Raízes; CV: Coeficiente de Variação.

Estes resultados corroboram com os obtidos por Araújo et al. (2008) e Manhães et al. (2011) que ao avaliarem o desempenho da forragem verde hidropônica de milho fertilizado com vinhoto como solução alternativa, constataram efeito significativo nas massas fresca e seca da forragem.

A Figura 3 apresenta os resultados da análise de regressão da produtividade da forragem, em termos de matéria fresca e seca da parte aérea (MFPA e MSPA), onde observa-se incremento linear a partir da aplicação de $2 \%$ de urina com manipueira, com coeficientes de determinação $\left(R^{2}\right)$ de $96,64 \%$ e $84,57 \%$, respectivamente (Figuras $3 \mathrm{~A}$ e $3 \mathrm{~B}$ ). $\mathrm{O}$ máximo incremento de massa fresca da parte aérea foi de 2,64\% referente à dose de $5 \%$ e 9,85\% para a massa seca, quando comparado com a testemunha.
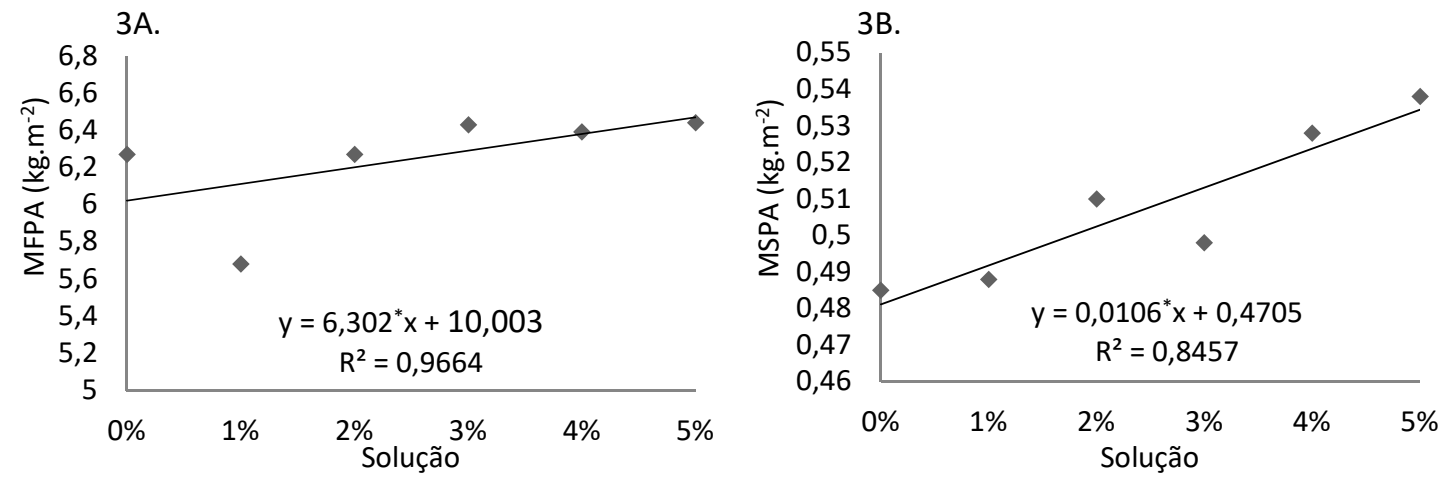

Figura 3: Produtividade da forragem em termos de massa fresca da parte aérea (MFPA, 3A) e massa seca da parte aérea (MSPA, 3B) em função das doses de urina associada à manipueira.

Paula et al. (2011), estudando o cultivo da forragem verde hidropônica de milho em substrato de bagaço de cana-de-açúcar fertilizado com doses crescentes de soro de leite bovino, constataram que à medida que aumentou as doses de soro de leite ocorreu um decréscimo linear nas massas fresca e seca da parte aérea e substrato com raízes da forragem.

Resultados contrários foram obtidos nesta pesquisa, pois em conformidade com as Figuras 3A e 3B à medida que foram aumentadas as doses de urina associada à manipueira, as massas fresca e seca da parte aérea da forragem também aumentaram, indicando efeito positivo dos tratamentos aplicados.

Uma provável explicação para os ganhos de massas fresca e seca na parte aérea da forragem é que os nutrientes presentes nas soluções foram bem aproveitados pelas plantas, indicando grande potencialidade nutricional dos resíduos utilizados na formulação das soluções nutritivas alternativas avaliadas nesta pesquisa. 


\section{CONCLUSÕES}

A urina humana associada à manipueira apresentou potencialidade para o uso como solução nutritiva alternativa a ser utilizada na fertilização de milho cultivado em sistema hidropônico com substrato de bagaço de cana-de-açúcar. As doses de 4 e $5 \%$ foram as que promoveram os maiores ganhos de macronutrientes e massa fresca e seca na parte aérea da forragem, respectivamente. A solução alternativa para o cultivo da forragem verde hidropônica de milho pode ser preparada a partir da urina humana diluída em água na concentração máxima de $5 \%$ acrescida de manipueira até ajustar o pH na faixa recomendada para o cultivo.

\section{REFERÊNCIAS}

AMORIM, D. M. B.; NOTARO, Í. A.; FURTADO, D. A.; GHEYI, H. R., BARACUHY, J. G. V.. Avaliação de diferentes níveis de salinidade da água utilizada na produção de forragem hidropônica de milho. Revista Brasileira de Engenharia Agrícola e Ambiental, Campina Grande, p.339-342, 2005.

APHA. American Public Health Association; AWWA American Water Works Association; WEF - Water Environment Federation. Standard Methods for the examination of water and wastewater. $21 \mathrm{ed}$. Washington, : APHA, 2005.

ARAÚJO, V. S.; COELHO, F. C.; CUNHA, R. C. V; LOMBARDI, C. T.. Forragem hidropônica de milho cultivado em bagaço de cana e vinhoto. Revista Brasileira de Milho e Sorgo, v.7, n.3, p.251-264, 2008.

ARAÚJO, N. C.; GUIMARÃES, P. L. F.; OLIVEIRA, S. J. C.; LIMA, V. L. A.; BANDEIRA, F. A.; ARAÚJO, F. A. C.. Quantificação da geração de resíduos em uma casa de farinha no Estado da Paraíba. Revista Monografias Ambientais - REMOA, v.13, n.5, p.3793-3799, 2014. DOI:

http://doi.org/10.5902/2236130814984

ARAÚJO, N. C.; COURA, M. A.; OLIVEIRA, R.; SABINO, C. M. B.; OLIVEIRA, S. J. C.. Cultivo hidropônico de milho fertirrigado com urina humana como fonte alternativa de nutrientes. Irriga, Botucatu, v.20, n.4, p.718-729, 2015. DOI: http://dx.doi.org/10.15809/irriga.2015v20n4p718

CONCEIÇÃO, A. A.; RÊGO, A. P. B.; SANTANA, H.; TEIXEIRA, I.; MATIAS, A. G. C.. Tratamento de efluentes resultantes do processamento da mandioca e seus principais usos. Revista Meio Ambiente e Sustentabilidade, v.4, n.2, p.118-130, 2013.

FAO. Organización de la Naciones Unidas Para la Agricultura Y Alimentación. Forraje verde hidropônico: manual técnico. Manual Técnico, Primera Parte. Santiago: Oficina regional de la FAO para América Latina y el Caribe, 2001.

KARAKA, T.; BHATTACHARYY, P.. Human urine as a source of alternative natural fertilizer in agriculture: A flight of fancy or an achievable reality. Resources, Conservation and Recycling, v.55, n.4, p.400-408, 2011. DOI: http://dx.doi.org/10.1016/j.resconrec.2010.12.008

LAMB, G. C.; BROWN, D. R.; LARSON, J. E.; DAHLEN, C. R.; DILORENZO, N.; ARTHINGTON, J. D.; DICOSTANZO, A.. Effect of organic or inorganic trace mineral supplementationon follicular response, ovulation, and embryo poduction in superovulated Angus heifers. Animal Reprodution Science, v.106, n.3-4, p.221-231, 2008. DOI: http://dx.doi.org/10.1016/j.anireprosci.2007.04.007

LOURO, C. A. L.; VOLSCHAN JR., I.; ÁVILA, G. M.. Sustentabilidade ambiental: Estudo sobre o aproveitamento de nutrientes da urina humana para fins agrícolas. Revista Eletrônica Sistemas \& Gestão, v.7, n.3, p.440-447, 2012.

MANHÃES, N. E.; SANT'ANA, J. G.; COELHO, F. C.; GARCIA, L. N. C.; LOMBARDI, C. T.; FRANCELINO, F. M. A.. Forragem de milho hidropônico cultivado em bagaço de cana-de-açúcar, com diferentes densidades de semeadura e concentrações de vinhoto. Cadernos de Agroecologia, v.6 n.2, 2011.

MARINI, F. S.; MARINHO, C. S. Adubação complementar para a mexeriqueira 'Rio' em sistema de cultivo orgânico. Revista Brasileira de Engenharia Agrícola e Ambiental, v.15, n.6, p. 562-568, 2011. DOI: http://doi.org/10.1590/S1415$\underline{43662011000600004}$

MAGALHÃES, A. G.; ROLIM, M. M.; DUARTE, A. S.; BEZERRA NETO, E.; TABOSA, J. N.; PEDROSA, E. M. R..

Desenvolvimento inicial do milho submetido à adubação com manipueira. Revista Brasileira de Engenharia Agrícola e Ambiental, v.18, n.7, p.675-681, 2014. DOI: http://dx.doi.org/10.1590/S1415-43662014000700001

MIHELCIC, J. R.; FRY, L. M.; SHAW, R.. Global potential of phosphorus recovery from human urine and feces. Chemosphere, v.84, n.6, p.832-839, 2011. DOI: http://dx.doi.org/10.1016/j.chemosphere.2011.02.046

MÜLLER, L.; SANTOS, O. S.; MANFRON, P. A.; MEDEIROS, S. L. P.; HAUT, V.; DOURADO NETO, D.; MENEZES, N. L.; GARCIA, D. C.. Produção e qualidade bromatológica de gramíneas em sistema hidropônico. Revista da FZVA, Uruguaiana, v.12, n.1, p.88-97, 2005.

PAULA, L.; ROLIM, M.M.; BEZERRA NETO, E.; SOARES, T. M.; PEDROSA, E. M. R.; SILVA, Ê. F. F.. Crescimento e nutrição mineral de milho forrageiro em cultivo hidropônico com soro de leite bovino. Revista Brasileira de Engenharia Agrícola e Ambiental, v.15, n.9, p.931-939, 2011. DOI: http://dx.doi.org/10.1590/S1415-43662011000900009 
RODRIGUES, R. C.. Métodos de análises bromatológicas de alimentos: métodos físicos, químicos e bromatológicos.

Pelotas: Embrapa Clima Temperado, 2010.

SILVA, F. C.. Manual de análises químicas de solos, plantas e fertilizantes. 2 ed. Brasília: Embrapa Informação Tecnológica, 2009.

SILVA, F. A. S.; AZEVEDO, C. A. V.. They assistat software version 7.7 and its use in the analysis of experimental data. African Journal of Agricultural Research (AJAR), v.11, n.39, p.3733-3740, 2016. DOl:

http://doi.org/10.5897/AJAR2016.11522

TOKARNIA, C. H.; DÖBEREINER, J.; PEIXOTO, P. V..

Deficiências minerais em animais de fazenda, principalmente bovinos em regime de campo. Pesquisa Veterinária Brasileira, v.20, n.3, p.127-138, 2000.

WILDE, D. Influence of macro and micro minerals in the peripartuiente period on fertility in dairy cattl. Animal Reproduction Science, v.96, n.3-4, p.240-249, 2006. DOI: http://doi.org/10.1016/j.anireprosci.2006.08.004

A CBPC - Companhia Brasileira de Produção Científica (CNPJ: 11.221.422/0001-03) detém os direitos materiais desta publicação. Os direitos referem-se à publicação do trabalho em qualquer parte do mundo, incluindo os direitos às renovações, expansões e disseminações da contribuição, bem como outros direitos subsidiários. Todos os trabalhos publicados eletronicamente poderão posteriormente ser publicados em coletâneas impressas sob coordenação da Sustenere Publishing, da Companhia Brasileira de Produção Científica e seus parceiros autorizados. Os (as) autores (as) preservam os direitos autorais, mas não têm permissão para a publicação da contribuição em outro meio, impresso ou digital, em português ou em tradução. 